\title{
UMA MOEDA IMPOSSÍVEL, UM CORPO INESGOTÁVEL A ECONOMIA SADIANA NO SÉCULO XX ENTRE GEORGES BATAILLE E PIERRE KLOSSOWSKI
}

\author{
Eduardo Jorge de Oliveira ${ }^{1}$
}

Resumo: Será feita uma leitura de D.A.F. de Sade em Pierre Klossowski, Sade Mon Prochain, 1947, e em Georges Bataille, La valeur d'usage de D.A.F. de Sade, O.C. II, 1929-1940, ao lado do prefácio dedicado a Justine, em 1958. A partir desses textos, serão discutidos os aspectos de uma economia sadeana como uma operação de mudança de valores literários ou como a decadência pode ser sustentada como um valor romanesco para a composição de um corpo impossível.

Palavras-chave: Sade, Klossowski, Bataille, economia, corpo.

\section{Sade e seu valor de uso: Bataille e a ciência do excremento.}

Talvez o primeiro aspecto a ser levado em consideração em uma leitura de Sade a partir de seus próximos, Pierre Klossowski e Georges Bataille, esteja no entendimento do uso do termo economia para tentar compreender o movimento da obra de um autor do século XVIII nas respectivas leituras desses dois autores controversos no século XX. Entender as relações a partir da economia, implica lançar um olhar à representação para, em seguida, encontrar uma composição entre os limites fraseológicos da escrita e os limites sociais reais, como se, pelo viés do romance sadiano, pudéssemos separar claramente esses dois aspectos. O que está no limite nessa economia são as formas morais ${ }^{2}$ acabadas em leis, na teologia, na ciência, no sistema filosófico e na própria ideia sobre os romances. A ideia sobre romance não pode vista apenas do ponto de vista metafórico, mas deve ser levada em consideração a partir de suas metamorfoses, fábulas, parábolas, provérbios, enfim, no embuste ficcional que nos permite esboçar uma economia polimórfica.

\footnotetext{
${ }^{1}$ Universidade Estadual de Campinas - UNICAMP. (Unicamp/Fapesp). E-mail: posedu@gmail.com

${ }^{2}$ A moral que Justine constatará seu reverso a duras penas, recusando-se a crer, estrutura-se a partir de uma forma esvaziada que a funda. Sendo a Virtude um objetivo sem fundo, Justine sempre é enganada e surpreendida. Por esse aspecto, o valor da moeda sadeana é o sofisma.
} 
Reivindicamos uma economia polimórfica a partir de Sade como uma estrutura capital da parte maldita e do seu dispêndio em moedas vivas, colaborando para as estruturas ficcionais de Bataille e de Klossowski. A ficção não se dissocia absolutamente do pensamento ensaístico. Aliás, os restos da primeira são absorvidos no segundo. Apresentada essa questão, é preciso pensar como um daqueles homens problemáticos, deslocados e desorientados da Revolução atravessaria essas épocas e, como os signos da libertinagem se transformariam em um valor de uso do impossível, como diria em outro contexto Denis Hollier, a propósito de um numismata como Georges Bataille ${ }^{3}$.

A libertinagem, sem dúvida, está coordenada com o nível de vida que imperava em uma sociedade em plena decadência ${ }^{4}$. No entanto, corremos o risco da abstração ao falar de modo genérico da libertinagem, uma vez que podemos nos lançar aos catálogos das perversões do marquês de Sade. Eles existem pela precisão, pelo detalhe e pela combinação minuciosa desses detalhes. A libertinagem para Sade não é abstrata se pensada em texto; aliás se ausentarmos Sade das perversões a quem emprestou seu nome, apagamos o termo sádico e suas derivações no gesto silencioso e impudico da leitura de suas fiç̧ões do excesso, como muito bem define Eliane Robert de Moraes. ${ }^{5}$ Não há de se negar o perverso na letra, nos quadros, nas cenas e nas descrições, e em todo o desejo que transborda da escrita, afinal, o texto é a cena do crime, é a alcova, é a cópula, é a morte, é o excremento. Grande desafio esse, o de retirar Sade do texto, sua Bastilha, sobretudo para aplicá-lo fora da literatura. Talvez com essa dimensão e sem nenhuma pedagogia, somos levados a compreender a imaginação libertina a partir da força do encadeamento das palavras.

Georges Bataille, por sua vez, em um carta aberta, destinada aos seus "camaradas atuais", possui o título que enfatiza o emprego do "valor de uso" de D. A. F. de Sade. A leitura de Sade aproxima-se de uma necessidade feita às escondidas. Para Bataille, a vida e a obra do marquês seria isso na prática, isto é, "não teriam um outro valor de uso que não fosse o valor de uso vulgar dos excrementos, existindo apenas um prazer rápido e violento de evacuá-los para não vê-los"-6. Precisamos, no entanto, nos deter um pouco nessa formulação para entender que Bataille tinha por objetivo a elaboração de uma polaridade forte, em uma leitura minuciosa de dois impulsos humanos dispostos em texto: excreção e apropriação.

\footnotetext{
${ }^{3}$ HOLLIER, "La valeur d'usage de l'impossible", p. VIII.

${ }^{4}$ KLOSSOWSKI, Sade, meu próximo. p. 53.

${ }^{5}$ MORAES, Lições de Sade. Ensaios sobre a imaginação libertina, p. 11.

${ }^{6}$ BATAILLE, Euvres Complètes II, p. 56. E ainda: "A partir de agora eu enuncio algumas proposições que permitem a introdução, dentre outros, dos valores estabelecidos pelo Marquês de Sade. Evidentemente, não se trata do domínio da impertinência gratuita, mas de modo bem direto na própria Bolsa onde escreve-se no dia a dia o crédito possível à vida dos indivíduos e das coletividades. BATAILLE, O.C. II, p. 57-58.
} 
A partir do breve panorama esboçado acima, Sade foi um autor importante para a noção de heterologia que encontramos em Bataille. Ao reunirmos a teologia com o capitalismo, percebe-se que o mundo homogêneo simplifica Deus pelo signo paternal. Deus se afastaria de elementos assombrosos e dos signos de degradação e podridão, ausentando-se, assim, das marcas materiais de um cadáver que são apagadas após a morte. Com essa argumentação, Bataille nos define a heterologia como a ciência de quem é todo um outro. Mas onde ele quer chegar com essa definição? Ao mesmo tempo tendo como fonte a religião, ele a utiliza para diferir seus argumentos, valendo-se da radicalidade das palavras, em uma leitura hagiológica para, depois, chegar à poesia.

O termo hagiologia talvez fosse mais preciso, mas seria necessário subentender o duplo sentido de agios (análogo a ambiguidade de sacer) como degradado e santo. Mas é sobretudo o termo escatologia (ciência do excremento) que mantém nas atuais circunstâncias (especialidade do sagrado) um valor expressivo incontestável, como duplo de um termo abstrato tal qual heterologia (BATAILLE, O.C. II, 1979, p. 61-62).

A ambiguidade e o polimorfismo da economia importante para Bataille destinada a composição posterior de sua "parte maldita" nos ajuda a compreender uma série de transformações inerentes a heterologia. O étimo em questão, hagios, o áplos (ájos), permite um uso "negro", ainda que de forma rara, tratando-se daquilo que é execrável. Mesmo que a etimologia nos forneça um caminho instável, por um jogo lúgubre e associativo, talvez seja preciso investigar, uma passagem, a de hagios para agios evocando o otium, um espaço vazio por excelência, a partir de uma vizinhança textual e social que se torna outra, dando lugar ao ornamento desnecessário ou ao impropério, como se, a partir de Bataille, pudéssemos separar o santo do louco e vice-versa. Resta-nos saber o limite do rigor da imaginação libertina proporcionado pela leitura de Sade para a referida mais-valia dos signos mais abstratos que operam na heterologia, descendo para aquilo que há de mais baixo no materialismo. Bataille, sem citar o nome de Marx, lança mão do "valor de uso" para ler o autor de Justine, encontrando uma infinita fonte de dispêndio, tal qual o sol:

Alguns pensadores se exaltam com a ideia de jogar por terra - por completo - os valores que já estão bem estabelecidos. Assim, afirmam com prazer que o homem mais subversivo de todos - o marquês de Sade - é também o que melhor serviu a humanidade. Segundo eles, nada pode ser mais correto. Trememos diante da ideia da morte e da dor (sejam elas nossas ou dos 
outros); o trágico ou o imundo nos aperta o coração; no entanto, o objeto de nosso terror tem, para nós, o mesmo valor do que o sol, que não é menos glorioso se desviamos da sua claridade nossos olhares reprovadores (BATAILLE, 1958, p. XXI).

A heterologia faz parte desse tremor, participa dele, ao observarmos a morte de um semelhante pelo pavor à nossa própria morte. A questão fundamental é que para Bataille, tratase de equiparar esse pavor à escrita. Nessa carta aberta, existem dois aspectos descritos por Bataille: a teoria heterológica do conhecimento (théorie hétérologique de la connaissance) e os princípios da heterologia prática (principes d'bétérologie pratique). No primeiro, Bataille reúne os princípios escatológicos da religião para chegar à poesia, onde a ambiguidade do termo sacer faz mais sentido. Uma economia que, enfim, se apropria do desgosto, mesmo porque a poesia, nos diz Bataille, quase sempre dependeu dos grandes sistemas históricos de apropriação ${ }^{7}$.

A poesia ou, de modo geral, a literatura de Bataille, vale-se dessa operação crítica que expropria e se apropria do universo sadiano com um certo recuo ou desvio. Isso acontece pelo simples fato do autor de História do olho participar duplamente da recepção de Sade: pelo ensaio e pela produção literária. Ele insere na sua obra uma "irrealidade prática dos elementos heterogêneos".-8, o que nos leva ao desenvolvimento do segundo tópico, isto é, dos princípios da heterologia prática: "a partir do momento onde esta irrealidade se constitui imediatamente como uma realidade superior tendo por objetivo eliminar ou degradar a realidade inferior vulgar, a poesia está reduzida ao papel de medida das coisas e, em contrapartida, a pior vulgaridade assume um valor de excrecência cada vez mais forte". ${ }^{-9}$. Esse seria o momento preciso que, pelo viés de Sade - essa moeda impossível, - Bataille elabora uma oposição a representação homogênea do mundo, compreendendo ainda todo e qualquer sistema filosófico e a própria revolução ${ }^{10}$. Mesmo que a revolução participasse de um sistema de excreção mecânico, a heterologia de Bataille não pode se restringir ao pulsional. Essa lição, ele aprendeu com Sade.

Nessa economia da excreção e da absorção podemos traçar as lições das jornadas de dezembro nos 120 dias de Sodoma. Uma verdadeira "manutenção do excesso", como enfatiza

\footnotetext{
7 BATAILLE, Euvres Complètes II, p. 62.

${ }^{8}$ BATAILLE, Euvres Complètes II, p. 62.

${ }^{9}$ BATAILLE, Euvres Complètes II, p. 62.

10 Para contextualizar é preciso citar o trecho integralmente: "Entendido que o termo excreção aplicado à Revolução deve de imediato ser entendido no sentido estritamente mecânico, além disso, etimológico da palavra. A primeira fase de uma revolução é a separação, isto é, um processo que conclui com a separação de dois grupos de forças onde cada um deles é caracterizado pela necessidade na qual um se encontra excluindo o outro. A segunda fase é a expulsão violenta do grupo que possuía o poder pelo grupo revolucionário" (BATAiLlE, Euvres Complètes II, p. 66).
} 
Eliane Robert Moraes, no prefácio à edição brasileira do referido livro. À narração de Champville, são acrescidas as notas minuciosas de um diário. A coprofagia integrara já há algum tempo as práticas libertinas. Nesse momento, a excreção é absorvida, e não apenas a merda, mas o vômito, o esperma, a urina, matéria que na economia narrativa produz corpos impessoais, impróprios dentro de uma didática que oscila entre a voz e a escrita, entre a lição e a aprendizagem. Os regulamentos são precisos. Eles sustentam, em números, a imaginação libertina. Por um lado, Sade busca dar corpo à abstração aritmética, por outro, os jogos combinatórios abstraem o corpo: os cus sem rosto (posto em imagem por Pasolini), examinados no detalhe, praticamente abstraído dos corpos. Engana-se quem pensa que a imaginação libertina não é rigorosa, pois é dessa arte combinatória que os detalhes sustentam a narrativa dos 120 dias de Sodoma, como o princípio da delicadeza (o mesmo que Roland Barthes encontrará justamente em Sade) com o cuidado até com a produção de excrementos:

De manhã, após algumas observações feitas sobre a merda dos sujeitos destinados às lubricidades, decidiram que precisavam provar uma coisa de que Duclos falara nas suas narrativas: isto é, a supressão do pão e da sopa em todas as mesas, exceto a dos senhores. Esses dois objetos foram subtraídos, mas redobraram, em compensação, as aves e caças. Não demoraram oito dias para perceber uma diferença essencial nos excrementos: ficaram mais suaves, derretiam melhor na boca, tinham uma delicadeza infinitamente superior, e acharam que o conselho de D'Aucourt à Duclos era o de um libertino verdadeiramente versado nesses assuntos (SADE, 2011, p. 2012).

A heterologia aciona no texto aquilo que certamente está excluído. Ela o absorve sob a forma de palavras - provavelmente sem nada desperdiçar, a ver a narradora exausta pedindo para se retirar da cena da orgia ainda nos 120 dias de Sodoma. Assim, provavelmente Georges Bataille tivesse em mente esse romance de Sade ao redigir este fragmento sobre a merda como um corpo estrangeiro absorvido nas frases sob os artifícios da linguagem que o exclui dos limites sociais reais, salvo eventualmente sob alguma condição hilária de uma anedota:

Na medida que a merda provoca o hilário, ela pode ser vista de modo análogo a outros corpos estrangeiros que provocam tais como os parasitas do corpo, os personagens eminentes (como objeto de caricaturas), os loucos, os mal adaptados e, sobretudo, as palavras introduzem de certo modo nas frases que os excluem (BATAILLE, 1979, p. 72). 
Nessa heterologia existe uma construção plástica, erótica, entre o excesso e o gasto, onde a complexidade das formas abjetas são, inclusive, risíveis. Com o riso, o erotismo e a morte, Bataille observava um retorno à animalidade, na qual, à guisa de uma revolução lúbrica, "a concepção heterológica da vida humana seria substituída por uma concepção primitiva" ${ }^{11}$. Se Bataille publicou em 1957 um livro intitulado $A$ literatura e o mal, há de se discutir a existência desse mal como uma investigação do limite do humano e, se buscarmos a "senha filosófica" de sua época, o primitivo seria praticamente uma utopia, cuja vizinhança poderia ser esboçada a partir de um ritual indígena mexicano de sacrifício (Potlach) e um romance de Sade.

No prefácio de Justine, publicado no ano seguinte, em 1958, ele escreve que "seria simples mostrar na regra o que se opõe à vida humana a uma livre animalidade (o animal em si tem sua regra, - que tem o mesmo sentido, mesmo as formas sendo menos claras, - mas tratase aqui da conduta animal, inumana do homem".12). Para Bataille, os extremos tornam indissociável a civilização e a barbárie ou a selvageria. Nessa junção a diferença é que os civilizados possuem a palavra enquanto os selvagens não a tem, ressaltando que a linguagem de Sade ao incorporar ao verbo a violência, ao mesmo tempo que estabelece uma forte ligação com a linguagem da vítima, levando em consideração sua situação carcerária na Bastilha quando ele escreve os 120 dias de Sodoma. Todavia, nessa economia, Sade não é vítima, ele é uma figura de dispêndio da e na linguagem literária, acenando para a impossibilidade do romance. Essa seria a base que sustenta sua legibilidade.

\section{Uma leitura como moeda viva: a variação de Klossowski.}

Sade, men próximo, publicado em 1947, foi traduzido no Brasil no início dos anos 80. Em um dos fragmentos do livro que consiste na pergunta "quem é o meu próximo?", Pierre Klossowski depura a fraternidade a ser discutida entre suas flutuações e contratos para pensarmos como as leituras ou as lições de Sade podem ser determinantes para desarmar metáforas frágeis que rapidamente ganham aderência à palavra "povo", como a própria "soberania popular":

Aliás não há mais que uma relação inteiramente aleatória do indivíduo com a soberania popular: não haverá fraternidade vivida porque a fraternidade só pode viver nas flutuações da sensibilidade que, sob o regime das instâncias abstratas, são apenas flutuações do erro. Entre justos não somente a fraternidade não é

\footnotetext{
11 BATAILLE, Euvres Complètes II, p. 69.

12 BATAILLE, "Préface", Justine ou les malheurs de la vertu, p. XXIX.
} 
mais manifesta, ela desaparece. Não há mais que indivíduos estranhos e indiferentes uns aos outros, indivíduos desobrigados uns para com os outros, isto a tal ponto que precisam se ligar por contrato: eis por que o regime da vontade geral, um povo de irmãos é apenas uma metáfora (KLOSSOWSKI, 1983, p. 84).

Existe uma ética impossível instaurada nessas flutuações da sensibilidade. Entre Bataille e Klossowski, encontramos uma incontornável comunidade que depende dessa flutuação, que rapidamente pode sucumbir ao equívoco ao qual Sade frequentemente oscila. Vejamos por exemplo o vínculo com o mundo exterior ao castelo nos 120 dias de Sodoma, que existe pelo contrato do casamento que os quatro libertinos, Curval, Durcet, Blangis e o Bispo fazem entre suas próprias filhas. Esse contrato, sabe o leitor, é uma flutuação da sensibilidade. Abordando uma dimensão ética impossivel, Klossowski situa Sade prisioneiro do Antigo Regime e do Novo. O que faz dele um prisioneiro de todos os regimes imagináveis e situações mais restritas, como a "senha filosófica de cada época", onde o homem não poderia agir de outro modo e a falta de liberdade nos reflexos fisiológicos. A ética impossível está ligada à formação de um corpo que é pura flexão, ao tônus das frases que absorvem mais que um corpo restrito à sua constituição fisiológica pode receber ou suportar.

Klossowski em sua literatura traduziu as elaborações mais ousadas desse espírito para tornar a literatura experiência ou, nos seus termos, simulacro. Pierre Klossowski escreveu que o simulacro se afasta da pretensão de fixar o que apresenta de uma experiência, o que implica em uma forma de inclusão de tudo que é contraditório ${ }^{13}$. Não à toa, posteriormente, Gilles Deleuze em um ensaio dedicado a Klossowski afirma que o corpo é linguagem porque ele é essencialmente "flexão".14. E a língua disposta em escrita é realmente o que perfura, ultrapassa, esburaca, rasga os orifícios que permeiam a relação (enfatizando) em texto da perversão com a estrutura (romance). Os corpos não preenchem uma forma vazia do romance, mas se movimentam, perfuram e são perfurados com as palavras - foi esse o esforço de Bataille - para exibir, assim, um "corpo glorioso" (Gilles Deleuze, a partir de Klossowski) ou um "corpo impossível" (Eliane Robert Moraes, a partir de Bataille).

\footnotetext{
${ }^{13}$ KLOSSOWSKI, La ressemblance, p. 24. Trata-se de um texto sobre Georges Bataille: "Du simulacre dans la communication de Georges Bataille”, publicado originalmente na revista Critique, n. 195-196, de 1963, e publicado posteriormente em La ressemblance, de 1984, livro, aliás, dedicado a uma reflexão mais ampla sobre o simulacro. Neste mesmo ensaio, Klossowski faz um percurso sobre a clássica discussão entre Georges Bataille, Jean Paul Sartre e Jean Hyppolite até chegar em uma noção importante para o pensamento de Heidegger, "o ser enquanto ser" (l'être en tant que l'être), buscado pelo filósofo em Hölderlin, Nietzsche, Rilke. (KLOSSOWSKI, La ressemblance, p. 28).

${ }^{14}$ DELEUZE, "Klossowski ou os corpos-linguagem". Lógica do sentido, p. 294.
} 
Esse corpo está à prova da Natureza e diante da impossibilidade de uma fraternidade fundada no regicídio, caímica, onde a conservação da existência justifica o crime, o assassinato, pelos mais sagrados impulsos da natureza. Sade comete a bybris ${ }^{15}$ ao escrever o excesso e, ao fazer isso, torna praticamente inviável a possibilidade que seu texto abandone a literatura para habitar impunimente as superfícies da imagem. Diante desse excesso e por dentro das frases, "o mínimo acréscimo, a mínima supressão, o menor ornamento são insuportáveis", dirá Michel Foucault, em $1975^{-16}$, a propósito de Sade. Prosseguindo pelo argumento de Foucault, pelo regime da escrita, os fantasmas estão fechados e a regulamentação é cuidadosamente programada ${ }^{17}$.

Os roubos, os crimes, os assassinatos, os envenenamentos, enfim, as situações de descontrole são organizadas em estruturas vacilantes que aproxima a morte de Luis XIV da distância produzida entre a existência divina e a prática soberana. Matando o rei, mata-se Deus, expia-se a culpa, pois, em nome da soberania popular o ambiente está propício para o livre exercício do crime na impunidade. O fato de coincidir duas situações sociais conturbadas e de transição da Revolução para Sade e das guerras para Bataille e Klossoswki, fez com que todo um mundo heterogêneo da literatura fosse explorado, não apenas pela leitura de Sade, mas pela recepção de Nietzsche (Sur Nietzssche, volonté de la chance, 1945 e Nietəsche et le cercle vicieux, 1967).

15 LACROIX, M.; MAGNIEN, V. üBeıs, Dictionnaire Grec-Français, p. 1913. "Mas também uma demência punida pelas leis" (nomos)." Também sobre a escrita do termo, sua origem e sobrevivência, lê-se: "O principal significado pode ser exprimido assim: hybris, essencialmente é um grave atentado contra a honra de alguém, suscetível de provocar a vergonha e conduzir à cólera e tentativas de vingança. Hybris é com frequência, embora não necessariamente, um ato de violência; trata-se de uma atividade deliberada, e o motivo típico de uma imposição de desonra, é um prazer de exprimir um sentimento de superioridade, mais que pela norma, pela necessidade ou desejo de riqueza. Ela também é a característica dos jovens e/ou ricos ou classes mais abastadas; com frequência ela é associada à embriaguez. Assim, boa parte da Hybris denota um comportamento geral ou atos específicos ao encontro de outros, em vez de atitudes, ela pode, no entanto, em diversas ocasiões, em textos que incitam à reflexãoou filosóficos, designar no leitor, o desejo ou uma atitude dirigida contra um indivíduo ou aos humanos em geral." Hybris, no texto de Atenas, pertencia à lei, mais precisamente ao que atentava à medida contra alguém, pois falava-se em cometer bybris contra alguém (FISHER, N. R. E. Hybris. A study in the values of honour and shame in Ancient Greece, p. 36). A definição de hubris que está melhor relacionada com o pensamento de Georges Bataille está no livro de Roberto Sasso. Georges Bataille. Le système du non-savoir. A bubris seria uma forma de ressoar a noite e uma espécie de barulho que perturba a escuta filosófica. Nesse aspecto o fragmento Heráclito citado por Sasso faz parte de algo fundamental para Bataille: o desregramento deve ser escutado mais que uma casa em chamas" (hubrin chrè sbennvai mallo è purkaén). SASSO, Georges Bataille. Le système du non-savoir. Une ontologie du jeu, p. 191-192.

${ }^{16}$ Pasolini ambienta Sade na república fascista de Salo. Esse dado assume grande importância para a estrutura do filme.

${ }^{17}$ FOUCAULT, "Sade, sargento do sexo". Ditos e escritos III, p. 370-374. 
Georges Bataille havia desenvolvido a noção de heterologia no ensaio La structure psychologique du fascisme, de $1933^{18}$. Ele faz uma crítica à superestrutura do marxismo, buscando compreender o modo de funcionamento das sociedades fascistas (e por que esse tipo de discurso atraiu muitos miseráveis) e toda sua capa homogênea baseada no mundo produtivo. Um dos pontos mais importantes desse texto está na existência social do heterogêneo, mais precisamente os elementos impossíveis de serem assimilados, constituindo uma diferença não explicável, avançando em terminologias como "tabu", "inconsciente", "profano". Citando o referido artigo de Bataille: "Fora das coisas sagradas propriamente ditas, que constituem o domínio comum da religião e da magia, o mundo heterogêneo compreende o conjunto de resultados do dispêndio improdutivo".-19, fazendo com que tudo o que a sociedade homogênea rejeita receba o nome ora de dejeto, ora de transcendente.

O argumento é distinto, mas o código é partilhado pela pergunta "quem é meu próximo?" com uma ciência de quem é todo um outro (outro exemplo de Bataille: a realidade homogênea da ciência é um modo de traduzir a realidade heterogênea do pensamento místico dos primitivos). Assim, ler Sade e participar das leituras que buscaram nesse controverso autor uma fonte, faz com que se eleve as próprias camadas homogêneas da literatura, - ficção de excesso, mas também excesso da ficção -, pois heterogêneo é tudo aquilo que não é absorvido. Sade excreta e absorve o próprio dejeto e a transcendência. A impotência da absorção de tais elementos faz com que essa economia seja necessária para transgredir (termo que historicamente perdeu sua força) as leis do mundo homogêneo. Esse foi, durante muito tempo, o código de conduta da literatura que Bataille incorporou à sua prática e pensamento.

No prefácio que Georges Bataille dedica a Justine, em 1958, pode-se entender que o regular mundo homogêneo possui suas irregularidades. O elemento mais simples, o pormenor que passaria desapercebido em um romance, ignorado pelas formulações de algum grande escritor - a partir do bom uso da língua -, desperta a atração erótica. Ao longo de sua escrita, Sade comprova a existência do gozo que ultrapassa as genitálias e a penetração, para ampliálo à cena, às narrações, aos crimes relatados, às mortes e a tudo que participa de modo irregular de uma fuga com volúpia. "Poderíamos dizer que o mérito essencial de Sade foi ter descoberto e bem exposto, na fuga voluptuosa, uma função da irregularidade moral".20, assina Bataille no mesmo prefácio.

Nos Infortúnios da Virtude, essa irregularidade a qual se referiu Bataille, passa a ter uma legibilidade nos sofismas de uma das personagens que mais atenta contra as virtudes da pobre e

\footnotetext{
${ }^{18}$ A definição de heterologia vem precisamente do ensaio que Bataille publicou 1933, "La structure psychologique du fascisme". BATAILLE, Euvres Complètes I, p. 339-371.

${ }^{19}$ BATAILLE, "La structure psychologique du fascisme". CEuvres Complètes I, p. 346.

${ }^{20}$ BATAILLE, "Préface". Justine ou les malheurs de la vertu, p. XXIX.
} 
indefesa Justine. Trata-se da senhora Dubois. No momento em que ela discursa contra uma das maiores pilastras cristãs, a piedade, após um assalto seguido de um triplo homicídio, os ladrões estabelecem uma relação fundamental que marca a diferença entre a economia do roubo e um princípio literário sadiano. No primeiro caso, o que existe é uma forma mimética da economia em vigor, afinal, rouba-se também com fins arbitrários para gerar algum tipo de riqueza ou acúmulo, que definitivamente não interessa a Sade. Esse é um limite de uma economia desmesurada tal qual encontraríamos nos 120 dias de Sodoma, no excerto traduzido por Alain François: "com pessoas assim, de pouco valiam os tesouros e, quanto aos crimes, vivia-se então num século em que ainda não eram investigados e punidos como começaram a sê-los desde então".21.

O fantasma do mínimo prazer é capaz de levar as mais imensas fortunas. No entanto, o roubo configura-se como uma paródia do sistema para acessá-lo a partir do que foi roubado. Atento a esse detalhe, Sade, ao dar luz a Dubois, faz com que ela discurse contra as leis e contra o roubo que objetiva manter uma boa margem de ganhos. Os ladrões se queixam do pouco que tinham a partilhar, alegando que a pouca quantidade de dinheiro não justificaria as três mortes que eles acabaram de cometer. Dubois explica que se deve calcular as coisas a partir dos interesses de cada um. Em seus argumentos, ela aponta o que detém os mais tolos na carreira do crime: a fraqueza de nossos órgãos, a falta de um espírito reflexivo e os preconceitos com os quais fomos criados, tais como os falsos terrores da religião e das leis. A partir de Dubois, essa ética impossivel de Sade reside na elaboração dos princípios de uma economia da dilapidação do corpo no espaço literário, ao mesmo tempo em que, em termos suplementares, a arbitrariedade das leis e de Deus é declarada, conforme precisa Pierre Klossowski, em O filósofo celerado. ${ }^{22}$ Enfatizamos o princípio literário de Sade porque seria por esse viés que sua ética passa a existir. Existindo fundamentalmente pela literatura, o espaço material de tudo aquilo que é impossível, Sade se encaixaria como um de seus próprios personagens, um falsificador de moedas, aquele que pôs um valor decadente para circular na economia em vias de mudança, criando um caminho que inviabiliza o humano sob o prisma da moral. E ele consegue isso por intermédio de cada caso singular de perversão que faz com que os mais sórdidos modos de vida existam pelas leis romanescas da verossimilhança e precisamente bem formuladas e polidas nas expressões da linguagem.

Quanto ao aspecto da experiência sadiana, Klossowski exprime a dupla relação com a sua própria interioridade, pois o mais elevado nível da língua descreve os crimes e as cenas de gozo, atingindo por uma variedade de personagens - que vai do ladrão de estrada ao juiz - a razão normativa da linguagem. Assim, mesmo quando um texto literário expressa um ato aberrante, fora da norma, ele se vale do espaço do nomos, isto é, da regra e da norma para

\footnotetext{
${ }^{21}$ SADE, D.A.F, 120 dias de Sodoma ou a escola libertina, p. 43.

${ }^{22}$ KLOSSOWSKI, "Le philosophe scélérat ". in SADE, D.A.F. Voyage d'Italie, p. 479.
} 
aumentar o campo dos sentidos até então adormecidos pela razão normativa. Essa é uma estratégia narrativa: "nada detém a libertinagem e não há nada como lhe impor limites para ampliar e multiplicar os desejos" 23 .

Os desejos se multiplicam pelo roubo, pelo crime, pela orgia, onde tudo acontece dentro da língua, tocando levemente o que está fora. Sade é preciso até nessa borda do texto: o limite com o real, com o gozo, com Deus como uma estrutura sintática e semântica na página para se constituir uma das mais iminentes falhas da linguagem. A partir da troca de perversões específicas, Sade "reorganiza explicitamente a insubordinação das funções do viver a partir da razão ateia" ${ }^{24}$, conforme escreve Pierre Klossowski, e substitui Deus "pela Natureza no estado de movimento perpétuo" 25 , tal como argumenta Georges Bataille, em A literatura e o mal. A partir de ambos os aspectos, provavelmente um dos mais contundentes gestos do marquês implica em questionar uma comunidade de riquezas pelo roubo: "o juramento de respeito às propriedades não compromete aquele que nada possui. Puni o homem negligente que se deixa roubar e não aquele que rouba e que se limita a seguir o primeiro e o mais sagrado dos impulsos da natureza, o de conservar a sua própria existência, não importa a que custo". ${ }^{26}$ Sade é uma moeda viva que circulou e que circula no espaço íntimo da literatura. Mesmo diante de um de seus livros fechados, esse espirito se mantém: a economia sadiana refundou o signo libertino longe dos castelos, dos bosques e das florestas, mas na formação do espaço da imaginação, apontando o limite do humano e, sem o isso, nem mesmo a extrema lucidez kantiana seria capaz de reluzir sozinha. Provavelmente pelo motivo econômico do corpo que encontraremos um argumento para endossarmos a pergunta que conduz do livro de Éric Marty, Pourquoi le XXeme siècle a-til pris Sade au sérieux? (Por que o século XX levou Sade a sério?).

\section{AN IMPOSSIBLE COIN, AN INEXHAUSTIBLE BODY THE SADEAN ECONOMY IN THE 20TH CENTURY BETWEEN GEORGES BATAILLE AND PIERRE KLOSSOWSKI}

Abstract: We have read D.A.F. de Sade in Pierre Klossowski's Sade mon prochain (1947) and Georges Bataille's La valeur d'usage La valeur d'usage de D.A.F. de Sade, O.C. II, (1929-1940), alongside the preface dedicated to Justine (1958). Based on these texts, we intend to discuss the aspects of a Sadean economy as an operation of shift in literary values, or how decadence can be sustained as a romanesque value as a means to composing an impossible body.

Keywords: Sade - Klossowski - Bataille - economy - body.

\footnotetext{
${ }^{23}$ SADE, D.A.F. 120 dias de Sodoma on a escola libertina, p. 480.

${ }^{24}$ SADE, D.A.F. 120 dias de Sodoma on a escola libertina, p. 481-482.

25 BATAILLE, La littérature et le mal, p. 83.

${ }^{26}$ KLOSSOWSKI, Pierre, Sade, meu próximo, p. 66.
} 


\section{REFERÊNCIAS BIBLIOGRÁFICAS}

BATAILLE, Georges. "Préface". Justine ou les malheurs de la vertu. Paris: Pauvert, 1958. . Cuvres Complètes I. Paris: Gallimard, 1987. . CEurres Complètes II. Paris: Gallimard, 1979.

DELEUZE, Gilles. Lógica do sentido. São Paulo: Perspectiva, 2007.

FOUCAULT, Michel. "Sade, sargento do sexo". Ditos e escritos III. Estética: Literatura e pintura, música e cinema. Rio de Janeiro: Forense, 2013.

HOLLIER, Denis. "La valeur d'usage de l'impossible". Documents. Vol. 1. Paris : Jean-Michel Place, 1992.

KLOSSOWSKI, Pierre. La ressemblance. Marseille: Ryôan-ji, 1984.

. "Le philosophe scélérat ". in SADE, D.A.F. Voyage d'Italie. Paris: Tchou, 1967. . Sade, meu próximo. Tradução: Armando Ribeiro. São Paulo: Brasiliense, 1983.

LACROIX, M.; MAGNIEN, V. v̋beıs. In: Dictionnaire Grec-Français. Paris: Belin, 1969.

MARTY, Éric. Pourquoi le XX'me siècle a-t-il pris Sade au sérieux? Paris: Seuil, 2011,

MORAES, Eliane Robert. Lições de Sade. Ensaios sobre a imaginação libertina. São Paulo: Iluminuras, 2011.

FISHER, N. R. E. Hybris. A study in the values of honour and shame in Ancient Greece. Wiltshire: Aris and Phillips, 1992

SADE, D.A.F. 120 dias de Sodoma ou a escola libertina. São Paulo: Iluminuras, 2011.

SASSO, Roberto. Georges Bataille. Le système du non-savoir. Une ontologie du jeu. Paris: Les Éditions de Minuit, 1978. 